\title{
Impairment of Epiglottic Movement
}

National Cancer Institute

\section{Source}

National Cancer Institute. Impairment of Epiglottic Movement. NCI Thesaurus. Code

C127240.

An observation of an individual's epig lottic movement during swallowing. 